\title{
Actions of Endogenous Opioids on NMDA Receptor-Independent Long-Term Potentiation in Area CA3 of the Hippocampus
}

\author{
Stephen H. Williams and Daniel Johnston \\ Department of Neurology and Division of Neuroscience, Baylor College of Medicine, Houston, Texas 77030
}

\begin{abstract}
The opioid peptides represent a major class of neurotransmitter in the vertebrate nervous system and are prevalent in the hippocampus. There is considerable interest in the physiological function of the opioids contained in the mossy fiber pathway. The release of opioids from mossy fibers shows a strong frequency dependence. Long-term potentiation (LTP) at this synapse, an NMDA receptor-independent form of LTP, also depends on high-frequency synaptic activity, and this has led to speculation that endogenous opioids may be a critical factor in LTP induction. Previous reports using extracellular recordings have provided evidence for and against a role for opioids in mossy fiber LTP. Using single-cell recording techniques, we have tested the hypothesis that endogenous opioids are required for mossy fiber LTP induction. We recorded from a defined population of synapses that had EPSCs with fast rise times, short latencies, and monophasic decays, consistent with
\end{abstract}

a proximally terminating synapse. The opioid antagonist naloxone prevented mossy fiber LTP in the rat, but had no effect on the commissural/associational system, a nonopioid-containing pathway. The action of naloxone was not mediated through disinhibition because $\mathrm{GABA}_{\mathrm{A}}$ receptors were pharmacologically blocked in these experiments. We also tested the hypothesis that variations in postsynaptic receptor subtype distribution between species might explain previous controversies regarding the role of endogenous opioids. In contrast to the rat, LTP of the mossy fiber field potential in guinea pig was not blocked by naloxone. Our data suggest that opioids may be the presynaptically released, frequency-dependent, associative factor for mossy fiber LTP induction.

Key words: LTP; mossy fiber; hippocampus; opioid; naloxone; CA3; NMDA-independent; species differences
Two major excitatory synaptic pathways of the hippocampal formation, the mossy fibers and the perforant path, contain a high density of opioid peptides (Gall et al., 1981; McGinty et al., 1983) and opioid receptors. (Crain et al., 1986; McLean et al., 1987; Mansour et al., 1995). The physiological role of these peptides is not clear, but behavioral studies indicate that dynorphin acts as a reinforcer for operant conditioning when injected into the hippocampus (Stevens et al., 1991). Initial attempts to define the cellular actions of opioids in the hippocampus using exogenous agonist application suggested that opioids were predominantly excitatatory, but that this was mediated through decreased activity of inhibitory interneurons (Zieglgansberger et al., 1979; Cohen et al., 1992). Detecting the actions of endogenously released opioids is more difficult. One problem is that, as with many neuropeptides (Lundberg et al., 1981; Jan and Jan, 1982; Lundberg and Hokfelt, 1983), the release of opioids is frequency-dependent-at the mossy fiber synapse the peptide is released only by stimuli of $\geq 10$ $\mathrm{Hz}$ (Wagner et al., 1990; Caudle et al., 1991) — and the frequencies are above those normally used in examining synaptic activity. This frequency-dependent release pattern has led to the suggestion that opioids play an important role in long-term potentiation (LTP) induction (Jaffe and Johnston, 1990; Derrick et al., 1991). Opioid receptor antagonists such as naloxone can indeed prevent

Received Jan. 11, 1996; revised March 11, 1996; accepted March 13, 1996.

This work was supported by Public Health Service Grants DA07954 (S.H.W.), MH44754 (D.J.), MH48432 (D.J.), and NS1 1535 (D.J.). We thank D.B. Jaffe, P.E. Schulz, and C. Colbert for comments on this manuscript.

Correspondence should be addressed to Dr. Daniel Johnston, Division of Neuroscience, 1 Baylor Plaza, Houston, TX 77030.

Dr. Williams' current address: Institute for Developmental Neuroscience, Peabody College, Vanderbilt University, Nashville, TN 37203.

Copyright $(1996$ Society for Neuroscience $\quad 0270-6474 / 96 / 163652-09 \$ 05.00 / 0$
LTP induction in both the mossy fiber pathway (Martin, 1983; Ishihara et al., 1990; Williams and Johnston, 1992; Derrick and Martinez, 1994b) and the lateral perforant path (Bramham et al., 1988; Xie and Lewis, 1991; Bramham, 1992). These effects may be mediated through the $\mu$ and $\delta$ receptor subtypes. In contrast, two other groups have suggested that endogenous opioids, acting through $\kappa$ receptors, depress synaptic transmission (Weisskopf et al., 1993; Terman et al., 1994). Furthermore, it has been suggested that naloxone does not prevent mossy fiber LTP induction (Weisskopf et al., 1993; Salin et al., 1995). Thus, despite extensive efforts by a number of groups, the exact role of opioid peptides in LTP induction remains controversial.

One impediment has been disagreement concerning the methods used to isolate mossy fiber responses from the numerous other fiber systems in the $\mathrm{CA} 3$ region. The $\mathrm{CA} 3$ region is much more complex anatomically than other areas of the hippocampus, and interpretation of field potential recordings is problematic, making it difficult to interpret LTP studics (Claiborne et al., 1993). Another question raised has been whether the well known differences in opioid receptor distribution observed between various species might contribute to differences in the actions of naloxone (McLean et al., 1987; Mansour et al., 1995). We have attempted to address these issues by performing experiments using intracellular voltage-clamp recording. We isolated excitatory synaptic currents with rapid rise times, consistent for a proximally terminating synapse (Spruston et al., 1993), that were similar to those described previously for mossy fiber synapses (Johnston and Brown, 1983; Williams and Johnston, 1991; Jonas et al., 1993). Using these well defined mossy fiber response characteristics, we have tested the actions of naloxone on NMDA receptorindependent LTP. 
Some of these data have appeared in preliminary form (Williams and Johnston, 1992; Williams, 1994).

\section{MATERIALS AND METHODS}

Brains were rapidly dissected from male Sprague-Dawley rats or guinea pigs (100-200 gm), and transverse hippocampal slices (400 $\mu \mathrm{m}$ thick) were prepared using a Mcllwain tissue slicer or a Vibratome (TPI). During the slicing procedure, solutions were kept at $4^{\circ} \mathrm{C}$ in artificial CSF (aCSF) lacking added calcium. Slices were then incubated in aCSF for 1-2 hr before recording. Normal aCSF contained (in mM): $124 \mathrm{NaCl}, 2.5$ $\mathrm{KCl}, 26 \mathrm{NaHCO}_{3}, 2 \mathrm{CaCl}_{2}, 1 \mathrm{MgCl}_{2}$, and 10 dextrose, and was continuously bubbled with $95 \% \mathrm{O}_{2} / 5 \% \mathrm{CO}_{2}$. Picrotoxin (10 $\left.\mu \mathrm{M}\right)$ and bicucullinc $(10 \mu \mathrm{M})$ were added to the aCSF during recording to block $\mathrm{GABA}_{\mathrm{A}}$ receptors during intracellular recordings. In these experiments, $\mathrm{CaCl}_{2}$ and $\mathrm{MgCl}_{2}$ were raised to $5 \mathrm{~mm}$ to prevent epileptiform discharges. Slices were maintained and experiments were performed at $32-35^{\circ} \mathrm{C}$ (range) in an interface-type chamber. All experiments were performed in the presence of $20 \mu \mathrm{M} \mathrm{D}(-)$-2-amino-5-phosphonovaleric acid (D-APV) in the bathing media, unless stated otherwise.

The following drugs were used in this study: $(+)-(5 \alpha, 7 \alpha, 8 \beta)-N$ methyl- $N$-[7-(1-pyrrolidinyl)-1-oxaspiro[4,5]dec-8-yl-benzenacetamide (U-69593), nor-binaltorphimine (nor-BNI), trans- $( \pm$ )-3,4-dichloro- $N$ methyl- $N$-[2-(1-pyrrolidinyl)-cyclohexyl]-benzeneacetamide (U-50488), dynorphin A (1-17), bicuculline, and naloxone (Research Biochemicals, Natick, MA); D-APV (Cambridge Research Biochemicals, Wilmington, DE); and picrotoxin (Sigma, St. Louis, MO). Drug solutions were made from dilution of aqueous stock in aCSF and bath-applied.

Recordings were made from pyramidal neurons in areas $\mathrm{CA} 3 \mathrm{~b}$ or CA3c of the hippocampus using $25-40 \mathrm{M} \Omega$ electrodes ( $3 \mathrm{M} \mathrm{KAc}$ or $2 \mathrm{M} \mathrm{CsAc}$ ), or with extracellular electrodes placed in stratum lucidum. Intracellular electrodes were routinely coated with Sigmacote (Sigma) to reduce capacitance. Signals were recorded using an Axoclamp 2A or 2B (Axon Instruments, Foster City, CA) in discontinuous current- and voltageclamp mode (sampling rate of 3-7 kHz). Analog filtering of signals at 1 $\mathrm{kHz}$ allowed for measurement of signals with a rise time of $1 \mathrm{msec}$ with an error of $\pm 5 \%$. Synaptic activity was generally monitored by measurement of the EPSP in current-clamp, but voltage-clamp measurements were also performed periodically during the experiment to monitor the EPSC. Input resistance was monitored throughout the experiment by small hyperpolarizing current injections. The headstage output of the Axoclamp was continuously monitored on an auxiliary oscilloscope. Data were further amplified and digitized on-line using either a DEC LSI 11/23 system running BASIC23, or a NeXT Turbo station running custom software.

Bipolar stimulating electrodes were fabricated from fine platinum/ iridium wire, with the diameter of each pole $\sim 25 \mu \mathrm{m}$. To activate the mossy fibers, electrodes were placed adjacent to the stratum granulosum (hilar side) in the superior blade of the dentate gyrus at a point close to the junction of the inferior and superior blades. It was often necessary to adjust the position of the stimulating electrode to clicit satisfactory synaptic responses after impalement of the neuron. In some experiments, a second electrode was placed in the stratum radiatum area of CA1 to activate axons of the commissural/associational system (C/A). Occasionally, antidronic activation of CA3 occurred, and in these circunnstances the stimulating electrode was moved to a new site. Stimuli were given at a rate of $0.2 \mathrm{~Hz}$ with a duration of $50 \mu \mathrm{sec}$ and an intensity $(50-500 \mu \mathrm{A})$ sufficient to elicit an EPSP of $\sim 10 \mathrm{mV}$. 'Tetanic stimulation consisted of three trains of $100 \mathrm{~Hz}$ (1 sec duration, applied over a period of $15 \mathrm{sec}$ ) given at the test-stimulus intensity under conditions of current-clamp. Extracellular electrodes were positioned so as to maximize the recorded current sink in the stratum lucidum area. Statistical comparisons were made using the $t$ test or sign-test with a significance level of 0.05 . An exponential fitting program, DISCRETE, was used to fit the decay of EPSCs and to determine the time constant of post-tetanic potentiation (Provencher, 1976).

Isolation of mossy fiber synapses from other synaptic inputs in the CA3 region is a formidable problem, partly because of the complexity of the synaptic circuitry in the region, but also because the mossy fibers represent a relatively sparse group of axons-there are $\sim 50$ mossy fiber contacts per CA3 neuron out of a total of 10-15,000 excitatory synapses (Amaral et al., 1990). When GABA inhibition is pharmacologically blocked, fast excitatory synaptic events can be measured in isolation (Williams and Johnston, 1991), but the problem of separating monosynaptic mossy fibers from other excitatory input remains. We have used a biophysical approach to select for monosynaptic mossy fiber responses,
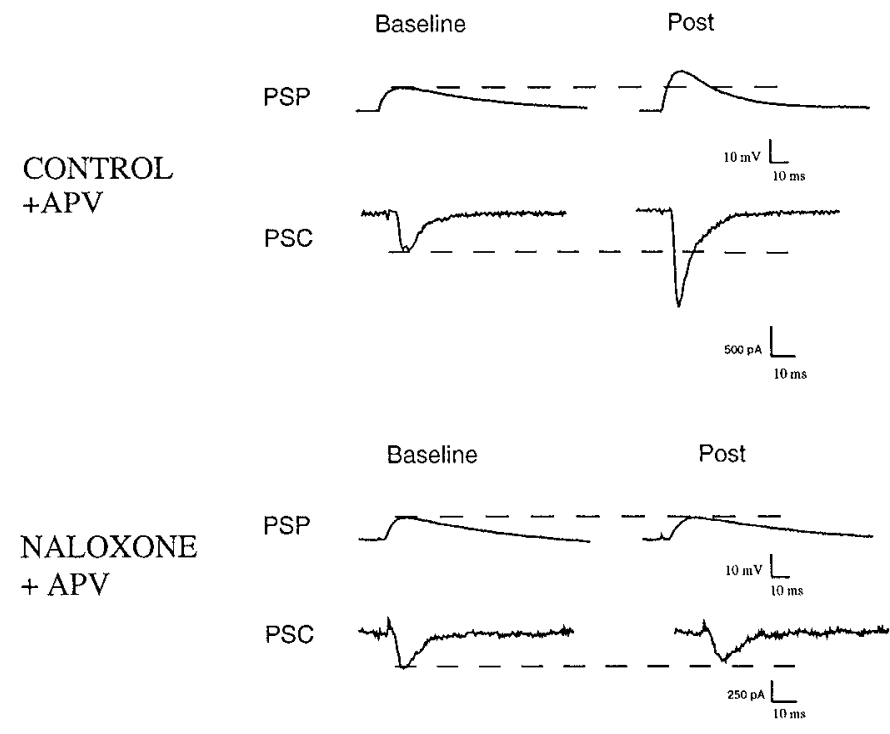

Figure 1. Naloxone blocks mossy fiber LTP. Example recordings from a control cell and a neuron bathed in $1 \mu \mathrm{M}$ naloxone using voltage recording (traces labeled $P S P$ ) or voltage-clamp (traces labeled $P S C$ ). After a period of recording EPSPs and EPSCs at $0.2 \mathrm{~Hz}$ (Baseline), three 1 sec, 100$) \mathrm{Hz}$ stimulus trains were delivered. After $15 \mathrm{~min}$, the control EPSP and ESPC clearly exhibited LTP (Post), whereas the naloxone-treated neuron did not. Twenty micromolar D-APV was present in both recordings. All measurements were made at approximately $-80 \mathrm{mV}$, and traces represent averages of $4-10$ consecutive traces.

taking advantage of the proximal location of mossy fiber terminals on the CA3 dendrite (Amaral and Dent, 1981; Brown and Johnston, 1983). Synaptic currents arising from these synapses have rapid rise times because the currents undergo relatively little electrotonic filtering (Jonas et al., 1993; Spruston et al., 1993). The following criteria were used to identify monosynaptic mossy fibcr responses: (1) short latcncy (4-6 msec depending on conduction distance); (2) $10-90 \%$ rise times of $\leq 2.5 \mathrm{msec}$; (3) single exponential decay of the EPSC; and (4) responses exhibiting monotonic rising and decaying synaptic currents under voltage-clamp.

These criteria are consistent with previous attempts to isolate pure monosynaptic mossy fiber inputs to CA3 (Williams and Johnston, 1991; Jonas et al., 1993; Xiang et al., 1994). Recordings were made from 231 rat CA3 neurons with resting potentials more hyperpolarized than $-50 \mathrm{mV}$. These cells had an average resting potential of $-55 \pm 2 \mathrm{mV}$ (mean \pm SEM), input resistance of $59.8 \pm 1.3 \mathrm{M} \Omega$, and membrane time constant of $34.3 \pm 0.8 \mathrm{msec}$. Approximately $40 \%$ of cells had synaptic currents with rise times of $<2.5 \mathrm{msec}$

\section{RESULTS}

Tetanic stimulation of the mossy fiber synaptic input to CA3 pyramidal neurons leads to a sustained potentiation of synaptic strength. This form of LTP does not depend on the activation of NMDA receptors, as is illustrated in Figure 1. In this example, the cell showed marked potentiation of both the EPSP and EPSC after tetanic stimulation, despite the presence of $20 \mu \mathrm{M} \mathrm{D}-\mathrm{APV}$. Consistent with previous studies (Williams and Johnston, 1989; Jaffe and Johnston, 1990), we found that, on average, mossy fiber synapses exhibit an $\sim 50 \%$ increase in EPSP or EPSC amplitude after tetanic stimulation (see Table 1).

To investigate the role of endogenous opioids in mossy fiber synaptic transmission, we incubated slices with $1 \mu \mathrm{M}$ naloxone, an antagonist that is effective against all three opioid receptor subtypes. Naloxone had no effect on baseline synaptic transmission ( $0.2 \mathrm{~Hz}$ stimulation frequency) under voltage- or current-clamp, indicating that under these conditions there is no opioid component to the EPSP. There was also no change in resting membrane potential, input resistance, or membrane time constant. When we 
Table 1. Effects of naloxone on mossy fiber ITP

\begin{tabular}{llll} 
Rat & Control & Naloxone & $t$ value \\
\hline EPSP (\% change) & $52 \pm 11$ & $-3 \pm 12$ & $3.24^{*}$ \\
$(n)$ & 17 & 13 & \\
EPSC (\% change) & $48 \pm 14$ & $-16 \pm 13.4$ & $2.84^{*}$ \\
$(n)$ & 18 & 10 & \\
LTP probability & 14 of 17 & 4 of 13 & \\
LTD probability & 1 of 17 & 5 of 13 & \\
Rise time (PSC) (baseline) & $1.5 \pm 0.1$ & $1.6 \pm 0.2$ & 0.53 \\
Rise time (PSC) (post-tetanus) & $1.6 \pm 0.2$ & $1.6 \pm 0.2$ & 0.11 \\
Decay time constant (baseline) & $8.2 \pm 0.7$ & $7.1 \pm 0.8$ & 0.94 \\
Decay time constant (post-tetanus) & $8.0 \pm 0.6$ & $6.1 \pm 0.5$ & 1.76
\end{tabular}

LTP generated cither in the presence of $20 \mu \mathrm{M} \mathrm{D}-\mathrm{APV}$ (control), or in $20 \mu \mathrm{M}$ $\mathrm{D}-\mathrm{APV}$ and $1 \mu \mathrm{M}$ naloxone, in the rat. LTP was measured as a change in EPSP or EPSC amplitude, $15 \mathrm{~min}$ after the tetanic stimulation (+ indicates an increase relative to pretetanus control; - indicates a decrease relative to control). Note there was significantly greater LTP in the control group compared with the naloxonetreated slices $\left(t\right.$ test) in both the EPSP and EPSC. ( ${ }^{*}$ denotes statistical significance.) Note that in three of the naloxone experiments, EPSC measurements were not made after tetanus because of oscillation during voltage clamping, or in one case because of an unacceptable increase in the resistance of the recording pipette. We also determined in each individual experiment whether LTP had occurred, defining LTP as $\geq 20 \%$ increase in response. In the naloxone group, the EPSP wals of terl significantly depressed aftcr tctanus ( 5 of 13 cells), whereas this was seen in only 1 of 17 control cells. Kinetic parameters of $10-90 \%$ risc-time and decay constant were measured beforc and after LTP induction. Clcarly there was no significant change in either parameter after LTP induction.

attempted to clicit LTP in the presence of naloxone, however, it was clear that the potentiation was blocked (Fig. 1B).

In the control group of cells, 15 min after the tetanus episode, there was a mean increase in EPSP amplitude of $\sim 50 \%$ (see Table 1). We observed a nearly identical change in the amplitude of the synaptic response measured under voltage-clamp. The probability of induction of LTP, defined as the proportion of cells exhibiting $a \geq 20 \%$ increase in EPSP amplitude (Hopkins and Johnston, 1988), was found to be $82 \%$ (14 of 17) under control conditions. In contrast, in cells that were tetanized in the presence of $1 \mu \mathrm{M}$ naloxone, there was no significant change in EPSP or EPSC amplitude (Table 1). The probability of LTP induction was significantly less in naloxone-treated cells (31\%;n=4 of 13) compared with control (sign-test). With one exception, the amplitude of LTP observed in naloxone-treated cells that exceeded the $20 \%$ criterion was modest (mean 27\%); this compared with $66 \%$ enhancement in control cells that exceeded the $20 \%$ criterion.

The time course of LTP induction can be appreciated by examining group data illustrated in Figure 2. After a period of baseline recording, cells in the control group were subjected to a tetanic stimulation train. This led to a large, transient potentiation (post-tetanic potentiation, or PTP) lasting a few minutes, followed by a sustained enhancement that persisted for the duration of the recording. The naloxone-treated cells also showed a transient potentiation after the tetanus, but the enhancement decayed to baseline within $2 \mathrm{~min}$, indicating that these cells lacked the sustained component of the potentiation.

In the naloxone group, there was negligible change in mean EPSP amplitude after tetanic stimulation for any time point beyond the PTP phase. However, in some cases (5 of 13) there was a significant drop in the EPSP amplitude after tetanus. This decrease was persistent and lasted for the remainder of the experiment. The decrease in EPSP was not accompanied by any changes in resting potential, input resistance, or membrane time constant. An example of two individual naloxone experiments is
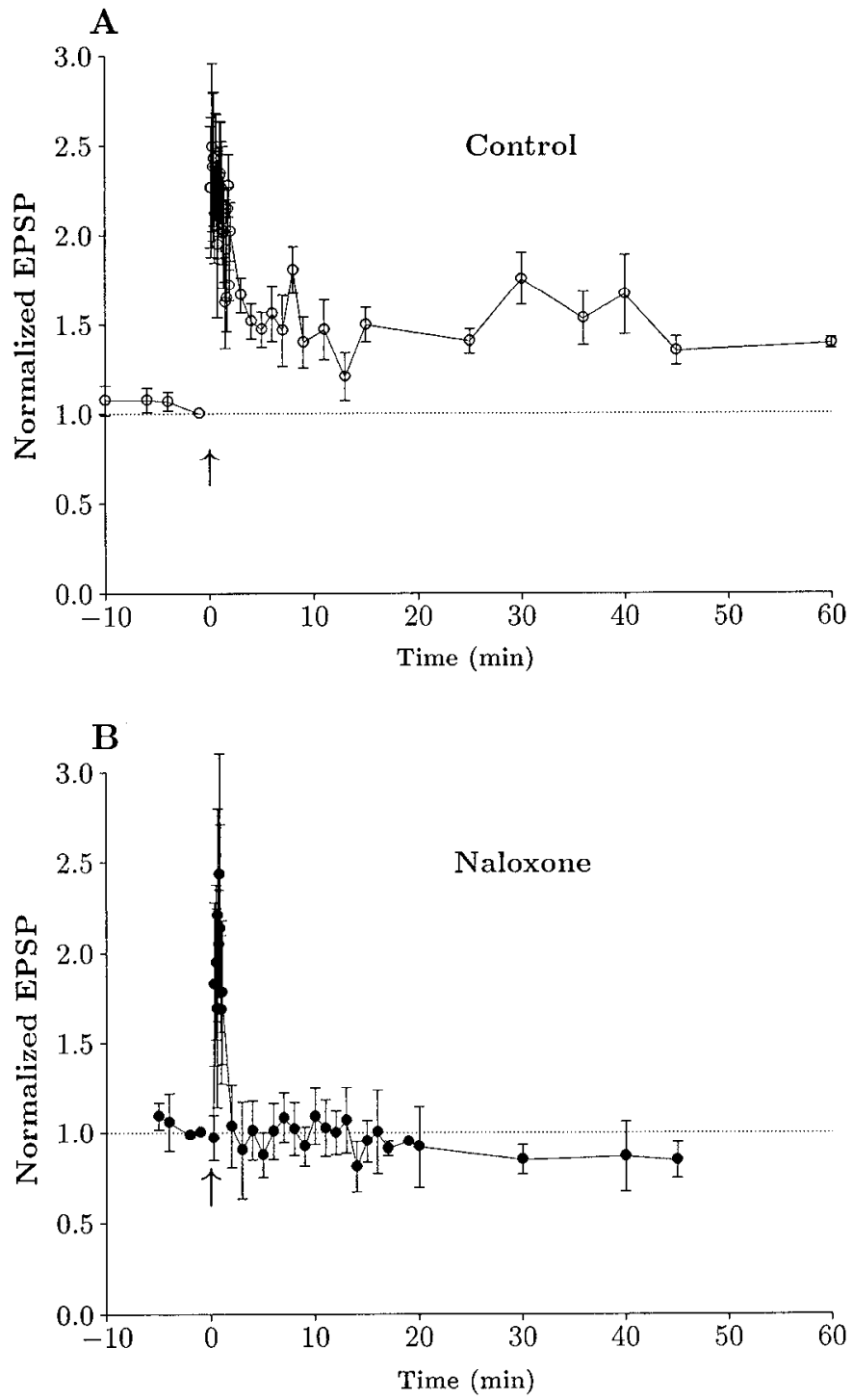

Figure 2. Average time course of mossy fiber LTP. Data have been grouped together and normalized to illustrate the time course of potentiation in the control group $(n=17)$ and naloxone group $(n=13)$. Data are from EPSP measurements that were normalized to the time point just before tetanic stimulation (1.0), illustrated by the dotted horizontal line. Time was normalized such that for each experiment, 0 represents the time at which high-frequency stimulation was delivered (denoted by an arrow). Each point is a mean value and bars are SEs. Data were collected continuously during the first $15 \mathrm{~min}$ after tetanus and subsequently were sampled every 5-10 min. Periodic determinations of EPSCs and passive membrane properties were made throughout the experiment. Both groups were clcarly potentiated for a brief period after high-frequency stimulation, but only the control group exhibited a sustained potentiation.

shown in Figure 3. The cell illustrated in Figure $3 A$ showed no significant increase or decrease after tetanic stimulation. In contrast, the cell scen in Figure $3 B$ showed a marked and sustained depression of the EPSP after tetanic stimulation. Because this phenomenon is reminiscent of other forms of synaptic depression seen in the hippocampus and cerebellum, we have, for convenience sake, termed this process long-term depression (LTD).

We next examined the temporal specificity of naloxone. In the experiments described so far, naloxone was added before tetanic stimulation and thus may be preventing the induction of LTP. It is possible, however, that naloxone could be blocking the mainte- 

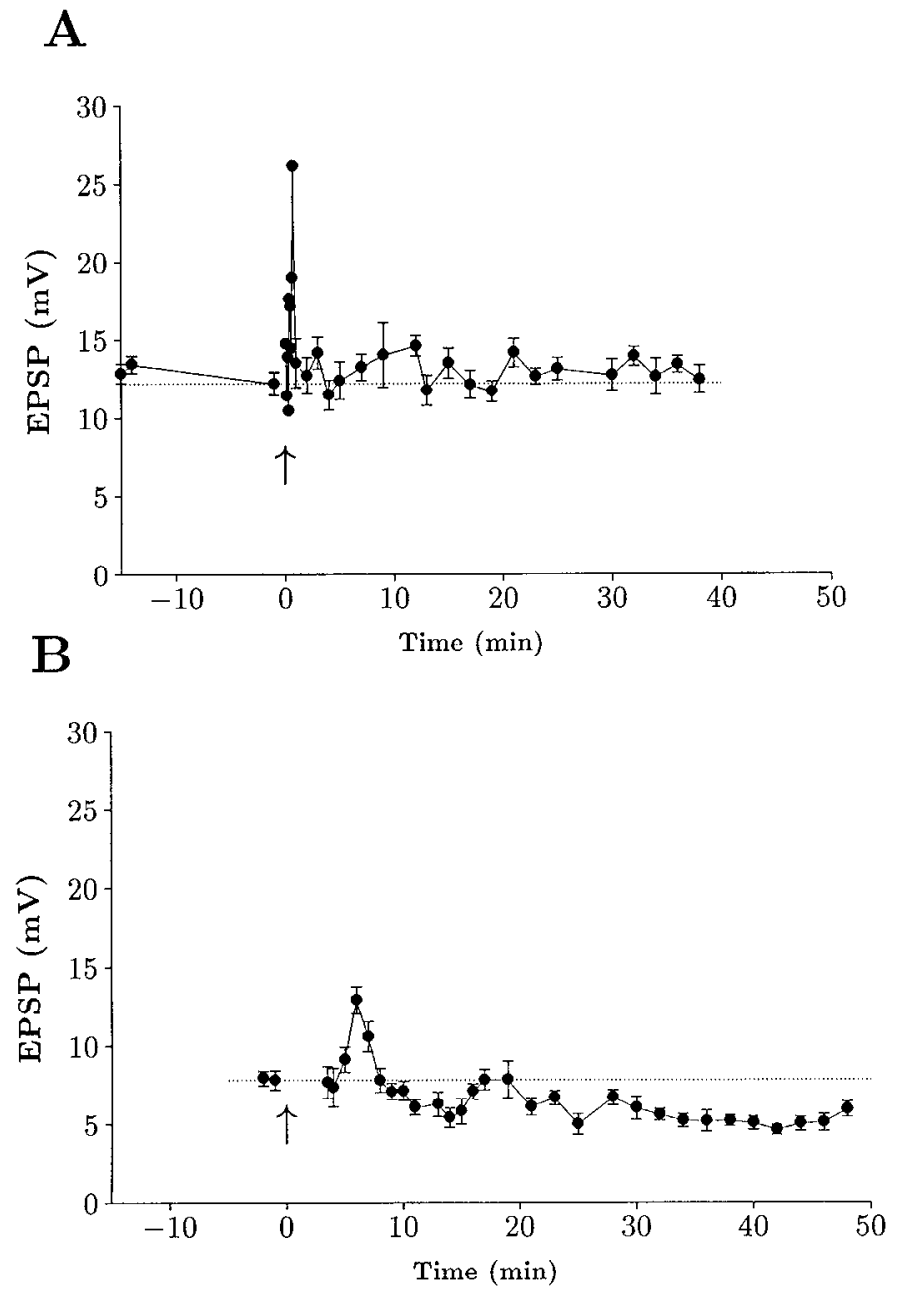

Figure 3. Naloxone can prevent LTP or cause a depression of response. $A$, Data from a single representative experiment in which there was no change in EPSP after tetanic stimulation. Points represent mean \pm SEM recorded over 30-60 sec periods, except during the PTP phase in which points represent single measures (no error bars). $B$, Data from a cell that exhibited a persistent depression of the EPSP after tetanic stimulation. Note that the EPSP remained depressed for the duration of the recording. (EPSP points were not measured during the PTP phase in this cell). The input resistance of this cell was $100 \mathrm{M} \Omega$ before tetanus and $109 \mathrm{M} \Omega$ after tetanus.

nance phase of LTP or antagonizing an opioidergic component of synaptic transmission apparent only after LTP. We have tested this possibility by inducing LTP and then adding $1 \mu \mathrm{M}$ naloxone. We found that naloxone had no effect on already established LTP (Fig. 4), suggesting that its action is specific to the induction stage of LTP. Similar results were obtained in a total of four cells.

As another test of the specificity of naloxone action, we attempted to elicit LTP in the C/A input to CA3. Because these synapses do not contain opioid peptides, naloxone should not prevent LTP in this pathway. In Figure 5, the $C / \Lambda$ input to a $C \wedge 3$ neuron was tetanized in the presence of $1 \mu \mathrm{M}$ naloxone, but in the absence of APV. LTP of both the EPSP and EPSC was observed. Similar results were obtained in a total of four cells. The effects of naloxone were therefore specific to the opioid-containing inputs to CA3, the mossy fibers.

We have gone to considerable lengths to isolate responses that have the characteristics predicted for a monosynaptic mossy fiber input (Brown and Johnston, 1983; Jaffe and Johnston, 1990;

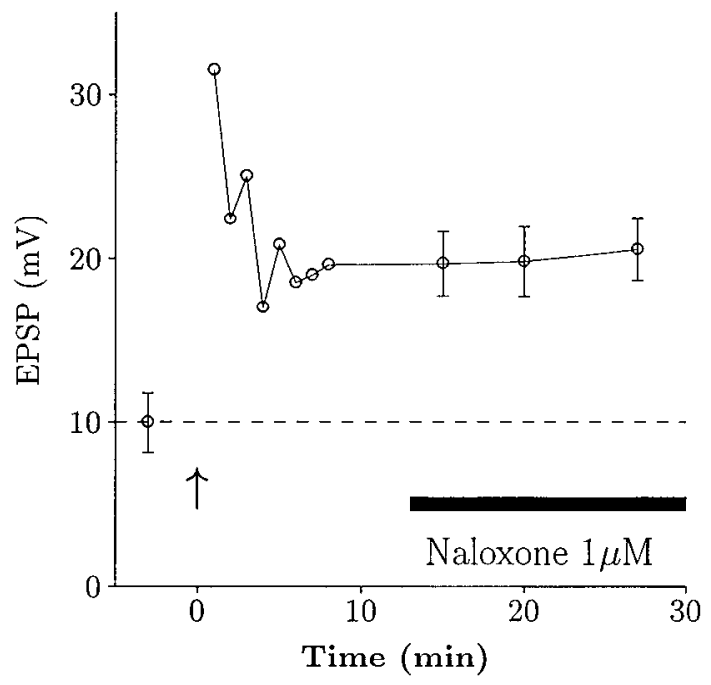

Figure 4. Naloxone does not affect established LTP. These data are from an experiment in which naloxone was added after LTP was established. Points with error bars represent a mean value from data collected over a 1-2 min period. Naloxone clearly did not ncclude I.TP that was already established.

Williams and Johnston, 1991; Claiborne et al., 1993; Jonas et al., 1993). During tetanic stimulation, however, it is likely that nonmossy fiber excitatory inputs will be activated and may influence the measured synaptic responses after the tetanic train, i.e., tetanus may recruit nonmossy fiber inputs (Miles and Wong, 1987). It is therefore crucial to demonstrate that the synaptic responses that follow LTP induction also meet the same selection criteria as were used to identify mossy fiber inputs at the beginning of the recording. Figure 6 illustrates an example of this type of analysis. In the control cell, despite a large increase in amplitude of the EPSC, there was no change in the $10-90 \%$ rise time or in the decay time constant of the waveform. This can be more fully appreciated by examining the normalized traces in which EPSCs are scaled to the same amplitude. $\Lambda$ similar result is illustrated for a cell from the naloxone group (Fig. 6, bottom). Although the EPSC is actually smaller after tetanus than baseline, the kinetics of the response was clearly unchanged. Summary data are shown in Table 1 for all cells used in this study. Note that there was no significant change in kinetics of the EPSC for either group of cells after tetanus.

The legitimacy of our selection procedure for mossy fiber responses will obviously depend on the criteria used to distinguish mossy from nonmossy inputs. Our choice of the $2.5 \mathrm{msec}$ cutoff for $10-90 \%$ rise time derives from comparisons of the kinetics of mossy fiber and C/A inputs to CA3 (Williams and Johnston, 1991). Although responses with the most rapid rise times are likely to represent more proximal synapses, the choice of a risetime cutoff is arbitrary. Therefore, we examined the data to determine whether the conclusions were upheld with more selective rise-time criteria. In Table 2, we show the effect of using increasingly faster rise-time limits on our LTP data. The conclusions are clearly unaltered by selection of synaptic inputs with more rapid rise times, suggesting that the measured responses are generated from a largely homogeneous group of synapses.

Our data are in reasonable accord with previous in vivo investigations of opioid actions on mossy fiber LTP in the rat (Derrick et al., 1991; Derrick and Martinez, 1994b). Yet these data seem hard to reconcile with data from guinea pig hippocampal slices 
Figure 5. Naloxone does not affect NMDA-dependent LTP of the C/A inEPSC were obtained in the presence of $1 \mu \mathrm{M}$ naloxone. Note that in this experiment no APV was present. put to CA3. LTP of both the EPSP and

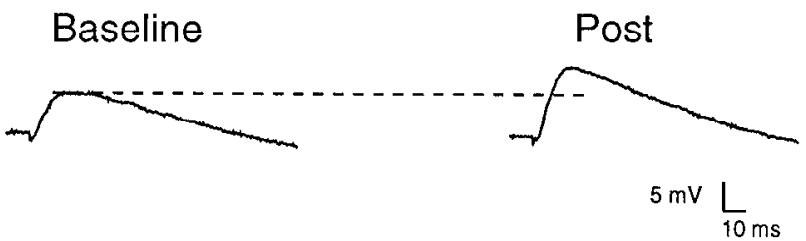

NALOXONE C/A

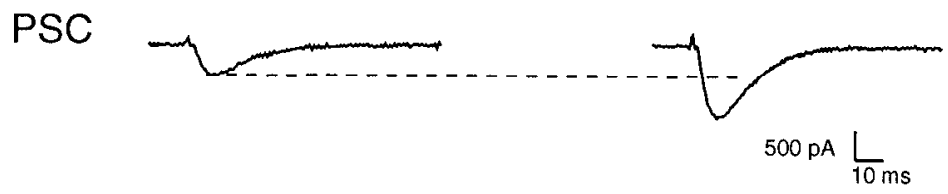

(Weisskopf et al., 1993). It is, however, well established that the pharmacological profile of opioid receptors in the CA3 region shows marked species variations. We decided to test the hypothesis that these species differences might account for some of these conflicting data. The most striking finding from Weisskopf ct al. (1993) was that low-frequency mossy fiber synaptic transmission was depressed by dynorphin acting on $\kappa$ receptors. In view of the low density of $\kappa$ receptors in the rat, we examined whether dynorphin would alter mossy fiber synaptic transmission. We found that $0.5-1 \mu \mathrm{M}$ dynorphin A (1-17) had no effect on mossy fiber synaptic transmission, measuring either the EPSP or EPSC. To ensure that this lack of effect did not represent a failure to record from mossy fibers, we also tested the actions of dynorphin on a response that had exhibited NMDA receptor-independent LTP. In the example shown in Figure 7, LTP was induced by our normal tetanus protocol and, after stabilization of the response at a new baseline level, dynorphin was bath-applied. Clearly, however, there was again no effect.

Because previous studies in the guinea pig (Weisskopf et al., 1993; Salin et al., 1995) had used extracellular recording tech- niques, we decided to directly compare rat and guinea pig slices under these conditions. For comparison purposes, we did not block GABAergic inhibition in these experiments. Once again we first induced LTP in the presence of APV to demonstrate that the measured field potentials were generated by mossy fiber synapses. An sample experiment is illustrated in Figure 8 . After induction of LTP and baseline stabilization, we applied the selective $\kappa$ agonist U69-593. (We chose not to use dynorphin in cases in which inhibition was intact, because although this peptide is most active against $\kappa$ receptors, it can also produce disinhibition working through $\mu$ receptors. Because these two effects would tend to counteract each other, we limited our observations to the more selective drugs.) Once again, we saw no effect in slices from rat (Fig. 8A). In contrast, however, we did see marked and consistent depressant effects in slices from guinea pig (Fig. $8 B$ ). These actions were very slow to wash out, but could be rapidly reversed by application of naloxone or $\kappa$-selective antagonist nBNI (Fig. $8 C$ ). Similar actions were seen in untetanized slices; i.e., no effect in rat, but a depression in guinea pig. Depression could also be observed in perforant path-evoked field potentials measured in
BASELINE POST
NORMALIZED

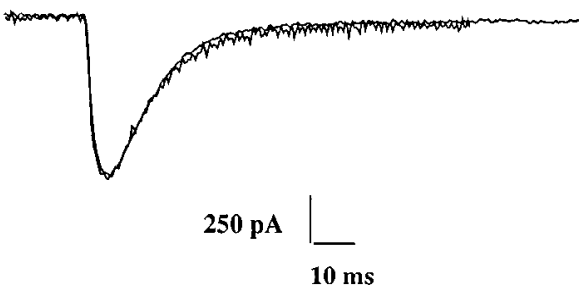

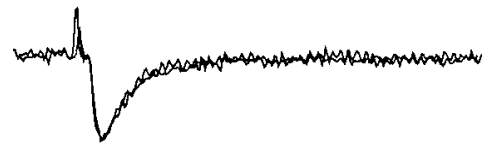

500 pA

$10 \mathrm{~ms}$

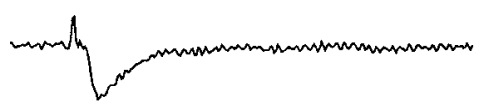

Figure 6. The kinctics of mossy fiber responses are unaltered after LTP. Top traces (D-APV) show the EPSC from a control cell before LTP induction (BASELINE) and after tetanic stimulation (POST). Clearly there was no change in the $10-90 \%$ rise-time or decay-time constant. This is illustrated in the far right panel in which the two responses are normalized to the same amplitude to allow a closer comparison. Similar data are shown for a naloxone-treated cell (D-APV+NAL) shown at the bottom. In this case, the EPSC was depressed after tetanus, but again the kinetics were unchanged. 


\begin{tabular}{|c|c|c|c|c|}
\hline \multirow{2}{*}{$\begin{array}{l}\text { Rise time } \\
\text { limit (msec) }\end{array}$} & \multicolumn{2}{|l|}{ Control } & \multicolumn{2}{|l|}{ Naloxone } \\
\hline & Mean rise time & LTP \% & Mean rise time & LTP \% \\
\hline$<2.5$ & $1.5 \pm 0.1$ & $52 \pm 11$ & $1.6 \pm 0.2$ & $-3 \pm 12$ \\
\hline$(n)$ & 17 & 14 of 17 & 13 & 4 of 13 \\
\hline$<2.0$ & $1.2 \pm 0.1$ & $54 \pm 15$ & $1.2 \pm 0.2$ & $-9 \pm 18$ \\
\hline$(n)$ & 14 & 12 of 14 & 8 & 3 of 8 \\
\hline$<1.5$ & $1.0 \pm 0.1$ & $40 \pm 16$ & $1.0 \pm 0.10$ & $-17 \pm 23$ \\
\hline$(n)$ & 9 & 7 of 9 & 6 & 2 of 6 \\
\hline$<1.0$ & $0.8 \pm 0.1$ & $62 \pm 30$ & 0.7 & -20 \\
\hline$(n)$ & 4 & 4 of 4 & 2 & 1 of 2 \\
\hline
\end{tabular}

This table illustrates the effect of increasingly stringent risc-time criteria on the control and naloxone data groups. The left column indicates the $10-90 \%$ rise-time limit (c.g., the bottom row shows cells with a rise time of $<1.0 \mathrm{mscc}$ ). Mean rise-time values are for all the cells that pass the particular rise-time criteria, and LTP percentage is the mean increase in EPSP amplitude. Note that data subsets with very stringent rise-time criteria still support the conclusion that naloxone blocks mossy fiber LTP induction.

the molecular layer of the dentate gyrus in guinea pig but not in rat (data not shown).

Given that mossy fiber synaptic transmission in the guinea pig exhibited rather different responses to opioid receptor agonists than the rat, we decided to test whether LTP in the guinea pig was naloxone-sensitive. In these experiments, $20 \mu \mathrm{m}$ D-APV was present during tetanic stimulation, but GABA receptor blockers were omitted. In the control group, we could elicit LTP in $\sim 50 \%$ of slices (14 of 29). Preincubation with $1 \mu \mathrm{M}$ naloxone had no effect on the probability of LTP induction ( 8 of 14). The amount of LTP observed in the two groups was also very sinilar, and its time course is illustrated in Figure 9. These data suggest that NMDA receptor-independent LTP does not depend on opioid receptor activation in the guinea pig.

\section{DISCUSSION}

Our data suggest that a frequency-dependent release of opioid peptides provides a necessary cofactor for LTP induction in the rat mossy fiber system. The use of voltage-clamp recordings has allowed us to define and characterize the kinetic characteristics of a population of proximally synapsing terminals, the responses of which were consistent with previous measurements of mossy fiber responses (Brown and Johnston, 1983; Williams and Johnston, 1991; Jonas et al., 1993). Our experiments also suggest that the previously described differences in opioid receptor subtype distribution between species (based on immunocytochemistry, in situ hybridization, and radioligand binding) are mirrored in different physiological responses, both to applied agonists and in LTP sensitivity to naloxone.

The observation that guinea pig mossy fiber responses were depressed by $\kappa$-selective agonists but rat were not is in reasonable accord with previous data suggesting that endogenous opioids in the rat mossy fiber and perforant path synapses facilitate LTP induction acting through $\mu$ or $\delta$ receptors (Bramham et al., 1988; Xie and Lewis, 1991; Bramham, 1992; Derrick et al., 1992; Derrick and Martinez, 1994a,b), whereas endogenously released opioids in the guinea pig depress synaptic transmission through $\kappa$ receptors (Wagner et al., 1993; Weisskopf et al., 1993). Previous receptor localization studies have suggested that the distribution of opioid receptor subtypes differs substantially between the two species (McLean et al., 1987; Caudle and Chavkin, 1990): in the CA3 region of rat, $\mu$ receptors predominate and $\kappa$ receptors are

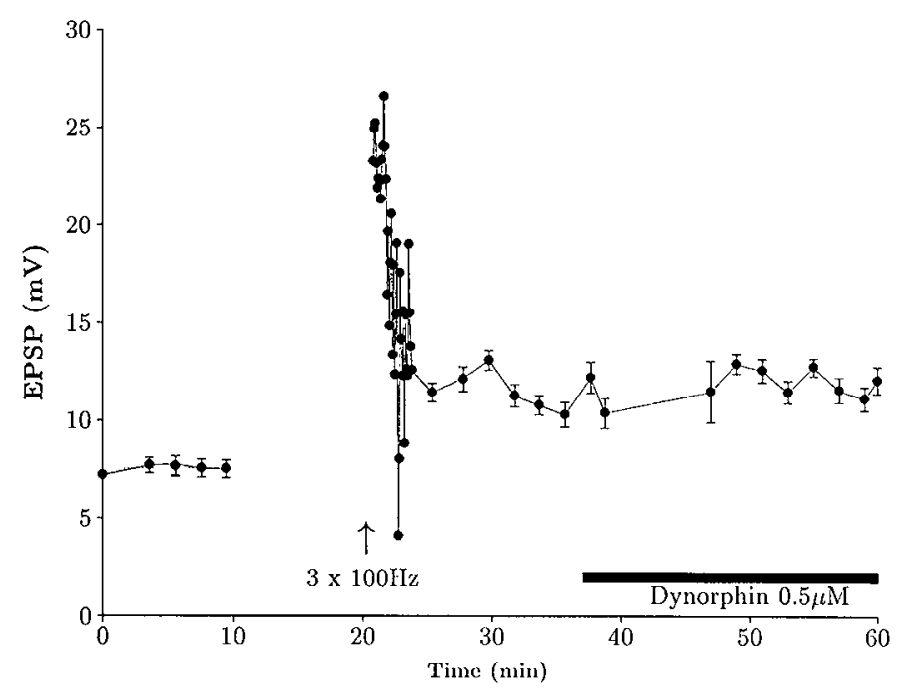

Figure 7. Dynorphin does not affect the rat mossy fiber EPSP. Intracellularly recorded mossy fiber LTP time course. LTP was elicited in a cell that had been bathed in $10 \mu \mathrm{M}$ picrotoxin, $10 \mu \mathrm{M}$ bicuculline, and $20 \mu \mathrm{M}$ D-APV. Subsequent perfusion of dynorphin A $(1-17)$ clearly did not affect the EPSP. This particular eell had an input resistance of $77 \pm 1 \mathrm{M} \Omega$ before drug application and $78 \pm 3 \mathrm{M} \Omega$ during drug application.

sparse (Mansour et al., 1995), whereas in guinea pig, $\kappa$ receptors are more prevalent. Our data and those of others (Caudle and Chavkin, 1990; Bramham, 1992; Derrick et al., 1992; Terman et al., 1994; Salin et al., 1995) support the idea that these receptor localization differences have important physiological consequences. However, although it has generally been found that opioid peptides have opposing actions in guinea pig (depressant) and rat (facilitatory), a few exceptions should be noted. Two studies have observed a block of mossy fiber LTP by naloxone in the guinea pig (Martin, 1983; Ishihara et al., 1990), and a recent report failed to block mossy fiber LTP in the rat (Salin et al., 1995). In the guinea pig studies, experiments were not performed in the presence of APV, and thus it is possible that LTP of NMDA-dependent synaptic inputs contributed to the measured responses. The experiments reported by Salin et al. (1995), however, were performed in APV, indicating that an NMDAindependent form of LTP can be elicited in the presence of naloxone. The presence of APV, however, does not guarantee that the LTP elicited is solely generated by mossy fiber synapses (Bradler and Barrionuevo, 1990). No raw traces were presented by Salin et al. (1995), so it is difficult to compare their mossy fiber response with those of the current study. From previous work, however, mossy fiber responses can differ considerably among groups (Williams and Johnston, 1991; Jonas et al., 1993; Weisskopf et al., 1993; Derrick and Martinez, 1994b; Xiang et al., 1994). This is most obvious when comparing response rise times and latencies, time course of LTP, and magnitude of LTP (Jaffe and Johnston, 1990; Zalutsky and Nicoll, 1990; Weisskopf et al., 1993; Derrick and Martinez, 1994b; Xiang et al., 1994). This suggests the possibility that these different responses are generated by two distinct synaptic pathways, or that mossy fiber response characteristics are extremely sensitive to small differences in experimental technique. Because it is currently not possible to determine which responses most closely describe the physiological characteristics of the mossy fibers, we and others believe that the selection of cells with fast monophasic EPSC kinetics is most likely to best represent the proximally terminating, monosynapti- 
A

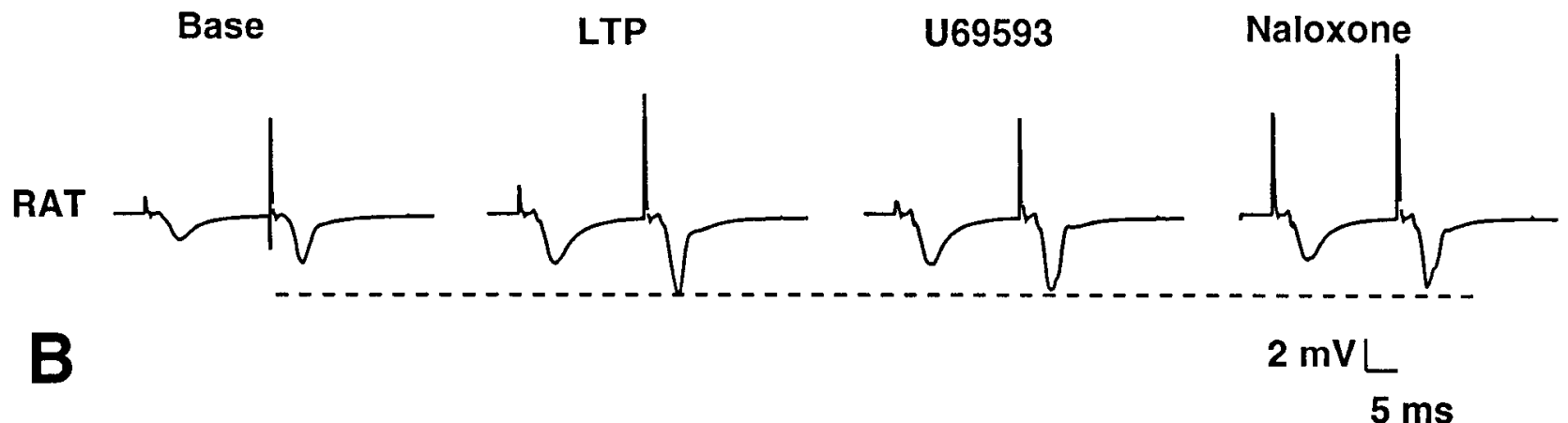

Base $\quad$ LTP $\quad$ U69593

nBNI

GP
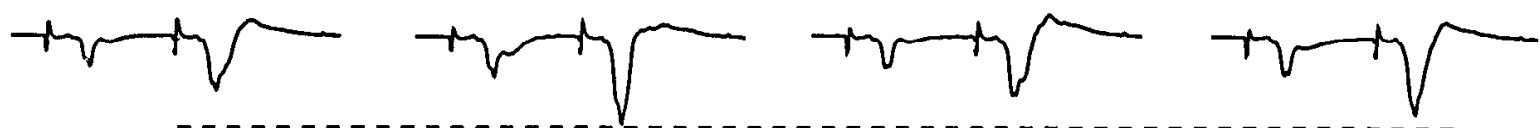

$1 \mathrm{mV}$

$5 \mathrm{~ms}$

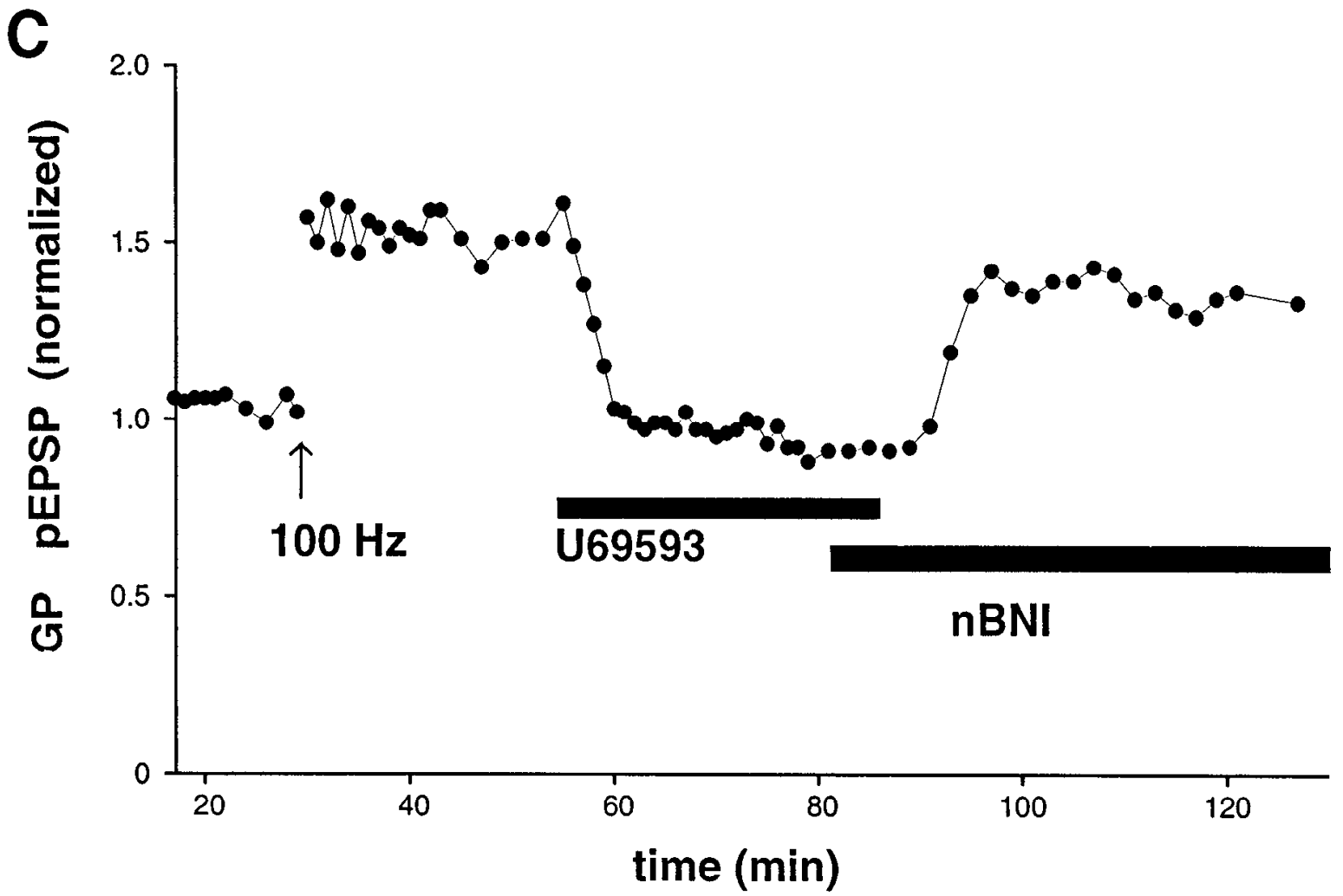

Figure 8. $\kappa$ opioids depress synaptic transmission in the guinea pig, but not in the rat. Mossy fiber field potentials were recorded in the stratum lucidum area of CA3 using paired-pulse stimulation protocol, and a baseline level of synaptic activity was measured (Base). To determine whether these field potentials were truly mossy fiber in origin, we elicited LTP in the presence of $20 \mu \mathrm{M}$ D-APV $(L T P)$, demonstrating that they were capable of showing NMDA-independent LTP. Application of U-69593 (U69593) at $2 \mu \mathrm{M}$ clearly depressed the guinea pig $(B)$ response but had no effect in the rat $(A)$. The depression was reversed by the $\kappa$-selective antagonist nor-BNI $(n B N I)$ at $1 \mu \mathrm{M}$. C, Time course of U-69593 (U69593) action in the guinea pig. Plot of pEPSP (normalized) over time. LTP was induced in the presence of $20 \mu \mathrm{M} \mathrm{D}-A P V$, and, after a new baseline was established, $2 \mu \mathrm{M}$ U-69593 was applied by bath perfusion. A dramatic reduction was observed in the response. The depression was reversed by nor-BNI $(n B N I)$ at $1 \mu \mathrm{M}$. (In the absence of antagonist, responses were poorly reversible at these doses.) 


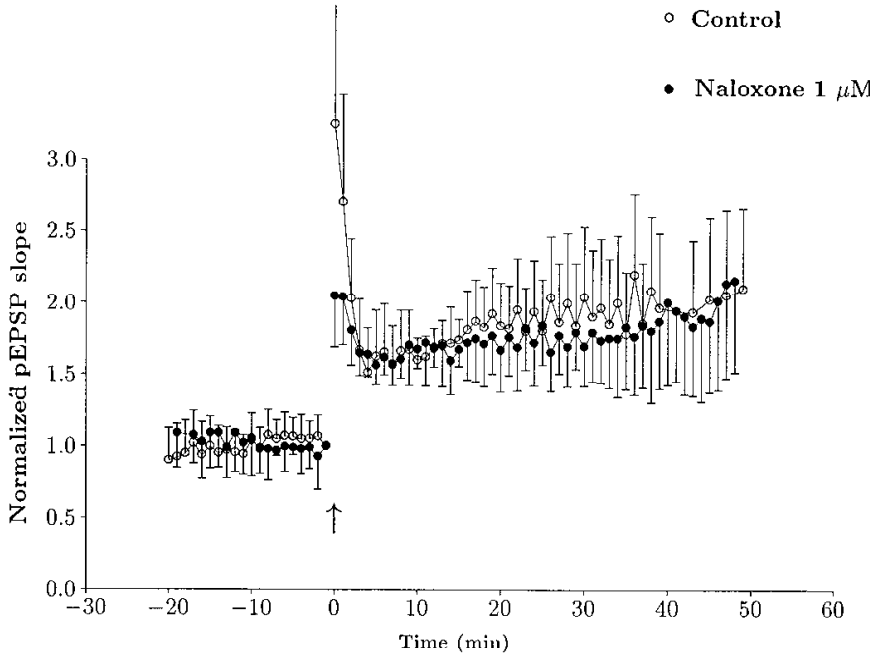

Figure 9. Naloxone has no effect on LTP in the guinea pig. Summary time course data from slices that exhibited LTP in control (open circles) and in the presence of $1 \mu \mathrm{m}$ naloxone (filled circles). Data are pEPSP slope measurements that were normalized to baseline values before tetanic stimulation (1.0), illustrated by the dotted horizontal line. Time was normalized such that for each experiment, 0 represents the time at which high-frequency stimulation was delivered, denoted by an arrow. Each point is a mean value, and bars are SEs. Both groups were clearly potentiated to a very similar degree.

cally activated mossy fibers (Johnston and Brown, 1983; Jaffe and Johnston, 1990; Williams and Johnston, 1991; Jonas et al., 1993; Spruston et al., 1993; Xiang et al., 1994; Urban and Barrionuevo, 1995).

A further consideration in dealing with the opioids is that these peptides are quite labile in the hippocampus. Large alterations in peptide precursor mRNA have been observed in response to LTP-generating stimulation patterns (Morris and Johnston, 1995). It is therefore possible that environmental factors might influence the levels of endogenous opioids before the experiment.

In our intracellular recording experiments from the rat, we found that naloxone specifically blocked the induction phase but not the expression phase of LTP. Furthermore, a nonopioidcontaining input to CA3, the C/A input, had normal LTP in the presence of naloxone. The observation that the presence of naloxone during tetanic stimulation could, in some cases, lead to a persistent decrease in response amplitude, or LTD, is interesting. Previous experiments in which mossy fiber LTP was simply prevented, either by postsynaptic injection of bis(2aminophenoxy)ethane- $N, N, N^{\prime}, N^{\prime}$-tetra-acetic acid (Williams and Johnston, 1989) or postsynaptic hyperpolarization during tetanus (Jaffe and Johnston, 1990), we observed no increase or decrease in EPSP amplitude. LTD of the mossy fibers has been reported, however, after tetanization of the fimbrial input to $\mathrm{CA} 3$ in the absence of mossy fiber stimulation (Bradler and Barrionuevo, 1990). These conditions are similar to those originally used to evoke LTD in dentate gyrus (Levy and Steward, 1979; Abraham and Goddard, 1983). Recent data from area CA1 suggest that LTD occurs when moderate stimulus frequencies elicit a modest increase in intracellular calcium levels (Bear and Malenka, 1994), conditions that have been termed anti-Hebbian (Lisman, 1989). For the case of the mossy fibers, if endogenous opioids are an associative factor for LTP induction, naloxone treatment may bring about an equivalent condition at this synapse, that is, highfrequency stimulation causing a postsynaptic elevation of calcium in the absence of a required associative factor (opioid peptide).
LTP induction at the mossy fiber synapse is dependent on high-frequency stimulation; pairing postsynaptic depolarization with single-afferent volleys is not sufficient to induce LTP (Jaffe and Johnston, 1990). Based partly on this observation, it has been proposed that mossy fiber synapses show a nonassociative form of LTP (Zalutsky and Nicoll, 1990). An alternate explanation, proposed by Jaffe and Johnston (1990), is that release of endogenous opioids might provide an associative factor, thereby providing a link between presynaptic activity and postsynaptic depolarization; mossy fiber LTP would be a Hebbian form of plasticity, but with induction rules slightly modified from synapses expressing NMDA-dependent LTP. Our data and other recent findings (Derrick and Martinez, 1994a; Urban and Barrionuevo, 1995) are certainly consistent with this hypothesis. It should be noted that a few cells did cxhibit modcst LTP in the presence of naloxone, possibly indicating that opioid peptides may not be an absolute requirement for mossy fiber LTP induction. Of course, our data do not rule out the possibility of other associative factors, and indeed experimental evidence suggests that norepinephrine (Hopkins and Johnston, 1984; Huang et al., 1994; Weisskopt et al., 1994) or glutamate acting through metabotropic receptors (Bashir et al., 1993) might fulfill such a role. Nevertheless, given the unique release pattern of the opioids and the additional observation that $\mu$ agonists can lower the cooperativity threshold for mossy fiber LTP (Derrick and Martinez, 1994a), the opioids remain the most likely candidate for a frequency-dependent associative factor under physiological conditions. It will be important to further elucidate the mechanism by which opioid peptides facilitate mossy fiber L'I'P induction.

\section{REFERENCES}

Abraham WC, Goddard GV (1983) Asymmetric relationship between homosynaptic long-term potentiation and heterosynaptic long-term depression. Nature 305:717-719.

Amaral DG, Dent JA (1981) Development of the mossy fibers of the dentate gyrus. I. A light and electron microscopic study of the mossy fibers and their expansions. J Comp Neurol 195:51-86.

Amaral DG, Ishizuka N, Claiborne B (1990) Neurons, numbers and the hippocampal network. In: Understanding the brain through the hippocampus: the hippocampal region as a model for studying structure and function, Vol 83 (Storm-Mathisen J, Zimmer J, Ottersen OP, eds), pp 1-11. Amsterdam: Elsevier.

Bashir ZI, Bortolotto ZA, Davies CH, Berretta N, Irving AJ, Seal AJ, Henley JM, Jane DE, Watkins JC, Collingridge GL (1993) Induction of LTP in the hippocampus necds synaptic activation of glutamate metabotropic receptors. Nature 363:347-350.

Bear MF, Malenka RC (1994) Synaptic plasticity: LTP and LTD. Curr Opin Neurobiol 4:389-399.

Bradler JE, Barrionuevo G (1990) Heterosynaptic correlates of longterm potentiation induction in hippocampal CA3 neurons. Neuroscience 35:265-271.

Bramham CR (1992) Opioid receptor dependent long-term potentiation: peptidergic regulation of synaptic plasticity in the hippocampus. Neurochem Int 20: 441-471.

Bramham CR, Errington ML, Bliss TVP (1988) Naloxone blocks the induction of long-term potentiation in the lateral but not in the medial perforant pathway in the anesthetized rat. Brain Res 449:352-356.

Brown TH, Johnston D (1983) Voltage-clamp analysis of mossy fiber synaptic input to hippocampal ncurons. J Neurophysiol 50:487-507.

Caudle RM, Chavkin C (1990) Mu opioid receptor activation reduces inhibitory postsynaptic potentials in hippocampal CA3 pyramidal cells of rat and guinea pig. J Pharmacol Exp Ther 252:1361-1369.

Caudle RM, Wagner JJ, Chavkin C (1991) Endogenous opioids released from perforant path modulate norepinephrine actions and inhibitory postsynaptic potentials in guinea pig CA3 pyramidal cells. J Pharmacol Exp Ther 258:18-26.

Claiborne BJ, Xiang Z, Brown TH (1993) Hippocampal circuitry complicates analysis of long-term potentiation in mossy fiber synapses. Hippocampus 3:115-121. 
Cohen GA, Doze VA, Madison DV (1992) Opioid inhibition of GABA release from presynaptic terminals of rat hippocampal interneurons. Neuron 9:325-335.

Crain BJ, Chang KJ, McNamara JO (1986) Quantitative autoradiographic analysis of mu and delta opioid binding sites in the rat hippocampal formation. J Comp Neurol 246:170-180.

Derrick BE, Martinez JL (1994a) Frequency-dependent associative longterm potentiation at the hippocampal mossy fiber-CA3 synapse. Proc Natl Acad Sci USA 91:10290-10294.

Derrick BE, Martinez JL (1994b) Opioid receptor activation is one factor underlying the frequency dependence of mossy fiber LTP induction. J Neurusci 14:4359-4367.

Derrick BE, Rodriguez SB, Lieberman DN, Martinez JL (1992) Mu opioid receptors are associated with the induction of hippocampal mossy fiber long-term potentiation. J Pharmacol Exp I'her 263:725-733.

Derrick BE, Weinberger SB, Martinez JL (1991) Opioid receptors are involved in an NMDA receptor-independent mechanism of LTP induction at hippocampal mossy fiber-CA3 synapses. Brain Res Bull $27: 219-223$

Gall C, Rrecha N, Karten H.J, Chang KJ (1981) I ncalization of enkephalin-like immunoreactivity to identified axonal and neuronal populations of the rat hippocampus. J Comp Neurol 198:335-350.

Hopkins WF, Johnston D (1984) Frequency-dependent noradrenergic modulation of long-term potentiation in the hippocampus. Science 226:350-352.

Hopkins WF, Johnston D (1988) Noradrenergic enhancement of longterm potentiation at mossy fiber synapses in the hippocampus. $J$ Neurophysiol 59:667-687.

Huang Y-Y, Li X-C, Kandel ER (1994) cAMP contributes to mossy fiber LTP by initiating both a covalently mediated early phase and macromolecular synthesis-dependent late phase. Cell 79:69-79.

Ishihara K, Katsuki H, Sugimura M, Kaneko S, Satoh M (1990) Different drug-susceptibilities of long-term potentiation in three input systems to the CA3 region of the guinea pig hippocampus in vitro. Neuropharmacology 29:487-492.

Jaffe D, Johnston D (1990) The induction of long-term potentiation at hippocampal mossy fibers follows a Hebbian rule. J Neurophysiol 64:948-960

Jan LY, Jan YN (1982) Peptidergic transmission in sympathetic ganglia of the frog. J Physiol (Lond) 327:219-246.

Johnston D, Brown TH (1983) Interpretation of voltage-clamp measurements in hippocampal neurons. J Neurophysiol 50:464-486.

Jonas P, Major G, Sakmann B (1993) Quantal components of unitary EPSCs at the mossy fibre synapse on CA3 pyramidal cells of rat hippocampus. J Physiol (Lond) 472:615-663.

Levy WB, Steward O (1979) Synapses as associative memory elements in the hippocampal formation. Brain Res 175:233-245.

Lisman J (1989) A mechanism for the Hebb and the anti-Hebb processes underlying learning and memory. Proc Natl Acad Sci USA 86:9574-9578.

Lundberg JM, Hokfelt T (1983) Cocxistence of peptides and classical neurotransmitters. Trends Neurosci 6:325-333.

Lundberg JM, Angaard A, Fahrenkrug J (1981) Complementary role of vasoactive intestinal polypeptide (VIP) and acetylcholine for cat submandibular gland blood flow and secretion. II. Effects of cholinergic antagonists and VIP antiserum. Acta Physiol Scand 113:329-336.

Mansour A, Fox CA, Akil H, Watson SJ (1995) Opioid-receptor mRNA expression in the rat CNS: anatomical and functional implications. Trends Neurosci 18:22-29.

Martin MR (1983) Naloxone and long term potentiation of hippocampal CA3 field potentials in vitro. Neuropeptides 4:45-50.

McGinty JF, Henriksen SJ, Goldstein A, Terenius L, Bloom FE (1983) Dynorphin is contained within hippocampal mossy fibers: immuno- chemical alterations after kainic acid administration and colchicine. Proc Natl Acad Sci USA 80:589-593.

McLean S, Rothman RB, Jacobson AE, Rice KC, Herkenham M (1987) Distribution of opiate receptor subtypes and enkephalin and dynorphin immunoreactivity in the hippocampus of squirrel, guinea pig, rat, and hamster. J Comp Neurol 255:197-510.

Miles R, Wong RKS (1987) Latent synaptic pathways revealed after tetanic stimulation in the hippocampus. Nature 329:724-726.

Morris BJ, Johnston HM (1995) A role for hippocampal opioids in long-term functional plasticity. Trends Neurosci 18:350-355.

Provencher SW (1976) An eigenfunction expansion method for the analysis of exponential decay curves. J Chem Phys 64:2772-2777.

Salin PA, Weisskopf MG, Nicoll RA (1995) A comparison of the role of dynorphin in the hippocampal mossy fiber pathway in guinea pig and rat. J Neurosci 15:6939-6945.

Spruston N, Jaffe DB, Williams SH, Johnston D (1993) Voltage- and space-clamp errors associated with the measurement of electronically remote synaptic events. J Neurophysiol 70:781-802.

Stevens KE, Shiotsu G, Stein L (1991) Hippocampal $\mu$ receptors mediate opioid reinforcement in the CA3 region. Brain Res 545:8-16.

Terman GW, Wagner JJ, Chavkin C (1994) Kappa opioids inhibit induction of long-term potentiation in the dentate gyrus of the guinea pig hippocampus. J Neurosci 14:4740-4747.

Urban NN, Barrionucvo G (1995) Induction of Hebbian and nonHebbian LTP at the hippocampal mossy fibcr synapse by distinct patterns of high frequency stimulation. Soc Neurosci Abstr 21:2006.

Wagner JJ, Caudle RM, Chavkin C (1990) Stimulation of endogenous opioid release displaces mu receptor binding in rat hippocampus. Neuroscience $37: 45-53$.

Wagner JJ, Terman GW, Chavkin C (1993) Endogenous dynorphins inhibit excitatory neurotransmission and block LTP induction. Nature 363:451-454.

Weisskopf MG, Zalutsky RA, Nicoll RA (1993) The opioid peptide dynorphin mediates heterosynaptic depression of hippocampal mossy fibre synapses and modulates long-term potentiation. Nature 362:423-427.

Weisskopf MG, Castillo PE, Zalutsky RA, Nicoll RA (1994) Mediation of hippocampal mossy fiber long-term potentiation by cyclic AMP. Science 265:1878-1882.

Williams SH (1994) Comparison of mossy fiber LTP in the rat and guinea-pig hippocampus. Soc Neurosci Abstr 20:715.

Williams SH, Johnston D (1989) Long-term potentiation of hippocampal mossy fiber synapses is blocked by postsynaptic injection of calcium chelators. Neuron 3:583-588.

Williams SH, Johnston D (1991) Kinetic properties of two anatomically distinct excitatory synapses in hippocampal CA3 pyramidal ncurons. J Neurophysiol 66:1010-1020.

Williams SH, Johnston D (1992) A novel action of endogenous opioids in the induction of hippocampal mossy fiber LTP. Soc Neurosci Abstr 18:403.

Xiang Z, Greenwood AC, Kairiss EW, Brown TH (1994) Quantal mechanism of long term potentiation in hippocampal mossy-fiber synapses. J Neurophysiol 71:2552-2556.

Xie C-W, Lewis DV (1991) Opioid-mediated facilitation of long-term potentiation at the lateral perforant path-dentate granule cell synapse. J Pharmacol Exp Ther 256:289-296.

Zalutsky RA, Nicoll RA (1990) Comparison of two forms of long-term potentiation in single hippocampal neurons. Science 248:1619-1624.

Zieglgansberger W, French ED, Siggins GR, Bloom FE (1979) Opioid peptides may excite hippocampal pyramidal neurons by inhibiting adjacent inhibitory interneurons. Science 205:415-417. 